\title{
Karakteristik Infrastruktur Pendukung Wisata Pantai Sanggar Kabupaten Tulungagung
}

\author{
Edwin Fahrur rozy, dan Arwi Yudhi Koswara \\ Departemen Perencanaan Wilayah dan Kota, Fakultas Teknik Sipil dan Perencanaan, \\ Institut Teknologi Sepuluh Nopember (ITS) \\ e-mail: arwiyudhi@gmail.com
}

\begin{abstract}
Abstrak-Pengembangan Wisata bahari lebih efektif apabila memanfaatkan potensi yang dimiliki sebagai basis pengembangan. Kecamatan Tanggunggunung memiliki potensi potensi wisata yang perlu didukung, sehingga memberikan pengaruh eksternal dalam mendukung kegiatan wisata di kawasan Pantai Sanggar. Salah satu bentuk dukungan yaitu penyediaan infrastruktur yang masih perlu untuk dilakukan pengembangan maupun peningkatan dalam mencapai tujuan yaitu memberikan dukungan terhadap kegiatan wisata. Oleh sebab itu, di perlukan pengembangan infrastruktur pendukung wisata. Penelitian ini menggunkan metode analisis deskriptif untuk mencari karakteristik infrastruktur pendukung wisata pantai sanggar. Peneliti ini menghasilkan karakteristik infrastruktur yang ada di pantai Sanggar. Kondisi infrastrukur bermacam macam mulai dari kondisi tidak ada sampai sampai ada, seperti infrastruktur yang sudah ada adalah kondisi jalan yang masih berupa macadam sepanjang kurang lebih $2 \mathrm{Km}$, tempat makan yang kondisinya masih sederhanya yang terdapat di desa Jelungharjo dan pantai Sanggar, tempat parkir yang menggunakan halaman rumah warga, penyediaan air bersih dan rambu rambu petunjuk jalan dan arah sudah tersedia yang ada di pintu masuk desa jenglungharjo dan di pantai, yang terakhir yaitu fasilitas amenitas yang berupa gazebo. Sedangkam untuk yang belum ada seperti pusat souvenir, kantor pusat informasi dan pelayanan, pos keamanan.
\end{abstract}

Kata Kunci-Pengembangan Infrastruktur wisata, wisata pantai.

\section{PENDAHULUAN}

$\mathrm{P}$ ERANAN pariwisata di Indonesia sangat dirasakan manfaatnya karena pembangunan dalam sektor pariwisata serta pendayagunaan sumber potensi kepariwisataan menjadi kegiatan ekonomi yang yang diandalkan untuk penerimaan negara, memperluas lapangan pekerjaan dan kesempatan berusaha bagi masyarakat setempat, mendorong pembangunan daerah Ayu, 2011. [1] Dengan gencarnya pasar pariwisata Indonesia, sebaiknya perlu di imbanginya dengan pengembangan potensi yang ada didaerah atau kawasan pariwisata. di dalam pengembangan suatu wilayah, infrastruktur merupakan suatu strategi dalam penyediaan sarana dan prasarana. Peran infrastruktur tidak hanya berpengaruh pada pengembangan wilayah saja, tetapi juga pada bidang kepariwisataan. Infrastruktur berperan sangat penting dalam mendorong kualitas wisata itu sendiri, serta pada lingkungan sekitarnya Dwi, 2005. [2]. Saat ini Kabupaten Tulungagung telah memiliki berbagai ragam obyek wisata pantai. Salah satunya adalah obyek wisata Pantai Sanggar yang terletak Desa Jengglungharjo Kecamatan Tanggunggunung RIPPDA Tulungagung, 2016. [3]. Fakta empiri Pantai Sanggar memiliki Ciri Khas dari Pemandanganya yaitu Tebing Jengger, dan Tebing Jalu, memiliki pasir pantai berwarna putih dengan ombak yang cukup besar. Kombinasi antara gelombang pasang surut dan angin lokal bertiup kencang menimbulkan ombak besar yang dapat menjadi salah satu daya tarik wisatawan untuk mengunjungi. Namun dari kelebihan yang dimiliki obyek wisata pantai sanggar, masih belum ditunjang oleh sarana dan prasarana yang memadahi, terutama dalam hal aksesibilitas dan infrastruktur menuju kawasan Pantai Sanggar Kabupaten Tulungagung. Selain itu, pantai sanggar ini belum didukung aksebilitas yang baik. Jalan menuju Pantai Sanggar rusak dan sempit, jalan masih berupa makadam, tanah liat PKS, 2016. [4].

Oleh sebab itu, dalam melakukan pengembangan wisata pantai Sanggar, di perlukan pengembangan infrastruktur pendukung wisata berdasarkan karakteristik yang ada di pantai Sanggar.

\section{TINJAUAN PUSTAKA.}

\section{1) Definisi pariwisata}

Pengertian pariwisata adalah proses bepergian sementara dari seseorang atau lebih menuju tempat lain di luar tempat tinggalnya. Dalam hal ini teori-teori yang digunakan ialah yang dikemukakan oleh suwantoro, Menurut Richard Sihite dalam Marpaung dan Bahar.

Tabel 1.

Definisi Parwisata

\begin{tabular}{llc}
\hline \hline SUMBER & Suwantoro (2004) & \multicolumn{1}{c}{$\begin{array}{l}\text { Richard Sihite dalam } \\
\text { Marpaung dan Bahar } \\
\text { (2000:46-47) }\end{array}$} \\
\hline & \multicolumn{1}{c}{$\begin{array}{c}\text { Pariwisata } \\
\text { Laktu }\end{array}$} \\
TEORI / & $\begin{array}{l}\text { Aspek sosial, ekonomi, } \\
\text { budaya, politik, agama, } \\
\text { kesehatan. }\end{array}$ & Lokasi \\
& $\begin{array}{l}\text { Menambah } \\
\text { pengetahuan/pengalaman. }\end{array}$ & Perencanaan \\
& & Rekreasi \\
\hline
\end{tabular}




\section{2) Daerah Tujuan}

Yoeti, (2006). [5]. tujuan wisata merupakan suatu keseluruhan atraksi, yaitu semua yang menjadi daya tarik wisatawan datang ke daerah tujuan wisata. Atraksi disini meliputi atraksi alam, atraksi budaya, atraksi sosial, dan atraksi buatan. Menurut Warpani (2007), [6]. Daerah Tujuan Wisata yang ideal harus memiliki daya tarik wisata yang menarik, mempunyai ketersediaan infrastruktur yang memadai, dan menawarkan pengalaman yang berkesan sehingga merangsang wisatawan untuk melakukan kunjungan ulang. Adapun Gunn (1994) memandang suatu daerah tujuan wisata terbentuk dari empat elemen pokok yang dapat mempengaruhi daerah tujuan wisata agar tetap hidup. [7]

Tabel 2.

Daerah Tujuan Wisata

\begin{tabular}{|c|c|c|c|}
\hline SUMBER & Yoeti (2006) & Warpani (2007) & Gunn (1994) \\
\hline \multirow{4}{*}{$\begin{array}{l}\text { TEORI } \\
\text { LITERATUR }\end{array}$} & \multirow[b]{2}{*}{ Atraksi. } & \multicolumn{2}{|c|}{ Daerah Tujuan Wisata } \\
\hline & & Daya tarik wisata. & Daya tarik \\
\hline & $\begin{array}{l}\text { Daya tarik } \\
\text { wisata. }\end{array}$ & $\begin{array}{l}\text { Infrastruktur yang } \\
\text { memadai. }\end{array}$ & Masyarakat \\
\hline & Lokasi. & $\begin{array}{l}\text { Menambah } \\
\text { pengalaman }\end{array}$ & Aksesbilitas \\
\hline
\end{tabular}

\section{3) Infrastruktur Pariwisata}

Pariwisata secara komprehensif merupakan suatu industri yang bergera di bidang pelayanan mempromosikan dari berbagai elemen yang terukur dan tidak dapat terukur. Elemen terukur antara lain sistem transportasi - udara, rel kerata, jalan air hospitality services - akomodasi, makanan, dan minuman, wisatawan OTW, dan souvenir, serta pelayanan yang berhubungan engan kegiatan wisata, misalnya bank, asuransi keamanan dan kenyamanan. Sementara itu elemen tidak terukur antara lain kegiatan istirahat, budaya pertualangan, serta pengalaman baru dan berbeda (WTO, 2006). [8]. Dalam hal ini teori-teori yang digunakan ialah yang dikemukakan oleh mc. Intosh, Inskeep, Musenaf, Nyoman s pendit, Yoeti. Sehingga mengasilkan sintesa pustaka sebagai berikut Tabel 3.

Sintesa Pustaka

\begin{tabular}{cll}
\hline \hline No & \multicolumn{1}{c}{ Indikator } & \multicolumn{1}{c}{ Variabel } \\
\hline 1 & Akomodasi wisata & $\begin{array}{l}\text { Fasilitas penginapan dan hotel } \\
\text { Jenis fasilitas yang digunakan } \\
\text { wisatawan selama melakukan } \\
\text { kunjungan }\end{array}$ \\
2 & Fasilitas amenitas & Restaurant atau tempat makan lainnya \\
3 & & Tempat parkir \\
4 & Fasilitas dan pelayanan & Kantor pusat informasi \& pelayanan \\
5 & wisata & Pos keamanan \\
6 & & Pusat oleh-oleh khas \\
7 & & Penyediaan air bersih \\
\hline \hline
\end{tabular}

\begin{tabular}{rll}
\hline \hline 9 & Jaringan listrik \\
10 & Tempat sampah \\
11 & Aksebilitas & Kondisi jalan \\
12 & & Rambu rambu petunjuk jalan arah \\
13 & & Moda transportasi \\
\hline \hline
\end{tabular}

\section{METODE ANALISA}

Pendekatan yang digunakan dalam penelitian ini adalah pendekatan rasionalisme yang bersumber pada teori dan kebenaran empirik. Jenis penelitian ini menggunakan pendekatan kualitatif yang bersifat deskriptif yang berguna untuk mendapatkan data primer maupun sekunder kemudian dianalisa untuk memperoleh hasil penelitian sesuai dengan tujuan penelitian.

Metode sampling yang ditempuh dalam penelitian ini adalah purposive sampling. Adapun yang dijadikan sampel penelitian adalah diperoleh stakeholder kunci dan stakeholder utama yang berpengaruh dan dapat memberikan informasi yang spesifik berdasarkan pandangan dan kepentingan kelompok sampel tersebut sebanyak dan seakurat mungkin.

Metode analisa yang digunakan dalam penelitian ini adalah metode analisa deskriptif untuk memaparkan karakteristik infrastrukur pendukung pariwisata wilayah studi.

\section{HASIL DAN PEMBAHASAN}

Identifikasi Karakteristik Infrastruktur Pendukung wisata Pantai Sanggar Kabupaten Tulungagung. Analisa ini bertujuan untuk menjabarkan karakteristik dari kawasan pantai Sanggar.

\section{A. Fasilitas penginapan}

\section{1) Kebijakan/teori}

Menurut kerjasama Direktorat Produk Pariwisata, Direktorat jendral Pengembangan Destinasi Pariwisata, Departemen Kebudayaan dan Pariwisata dan WWFIndonesia (2009). Salah satu aspek kunci Pengembangan ekowisata berbasis masyarakat yaitu memenfaatkan fasilitas penginapan berupa homestay yang menjadi pilihah utama untuk sarana akomodasi di lokasi wisata.

2) Kondisi eksisting

Tempat penginapan untuk wisatawan sehingga wisatawan harus menginap di hotel yang berjarak cukup jauh (kota) atau memilih camping di Pantai Sanggar.

3) Analisis

Pada kawasan wisata Pantai Sanggar Desa Jengglungharjo belum terdapat fasilitas penginapan. Seharusnya disediakan di sekitar kawasan pantai sanggar bisa memanfaatkan rumahnya sebagai homestay bagi wisatawan.

\section{B. Fasilitas amenitas}

1) Kebijakan/teori

Dalam pengembangan infrastruktur pendukung ekowisata yang seharusnya tidak menimbulkan 
kerusakan pada lingkungan seperti menggunakan sumberdaya ramah lingkungan berbahan kayu, dan bahan daur ulang. (from, 2004 dalam damanika dan webber, 2006).

2) Kondisi eksisting

Kawasan tersebut sudah memiliki fasilitas amenenitas (tempat duduk) di kawasan Pantai Sanggar.

3) Analisis:

Kawasan wisata Pantai Sanggar Desa Jengglungharjo sudah memiliki fasilitas amenitaas berupa tempat duduk yang ramah lingkungan dengan bahan kayu.

\section{Tempat makan}

\section{1) Kebijkan/teori}

Menurut Peraturan Direktur Jendral Perlindungan Hutan dan Konservasi alam tentang Pembangunan Sarana Pariwisata. bentuk bangunan yang dibangun semi permanen dengan ukuran panjang, lebar dan tinggi bangunan disesuaikan dengan memperhatikan kondisi fisik kawasan untuk realisasi tempat makan yang menjual makanan yang berbasis produk lokal bukan berbahan baku impor.

2) Kondisi eksisiting

Untuk tempat makan sudah tersedia 2 unit tempat makan dengan kondisi yang masih sederhana. 1 unit tempat makan berada di kawasan Pantai Sanggar dan satu lagi berapa di sekitar rumah warga.

3) Analisis

Kawasan Pantai Sanggar sudah tersedia tempat makan yang kondisinya masih sederhana. Tempat makan yang ada dikawasan pantai kondisi bangunannya telah sesuai semi permanen dengan ukuran panjang, lebar dan tinggi bangunan disesuaikan dengan memperhatikan kondisi fisik kawasan.

\section{Tempat parkir}

\section{1) Kebijakan/teori}

Menurut Peraturan Direktur Jendral Perlindungan Hutan dan Konservasi alam tentang Pembangunan Sarana Pariwisata. Fasilitas untuk menunjang sarana kepariwisataan berupa areal parkir sebagaimana dibangun dengan ketentuan tidak menebang/merusak pohon, pengerasan areal harus dilakukan dengan kontruksi yang tidak mengganggu penyerapan air dalam tanah.

2) Kondisi eksisiting

Untuk fasilitas tempat pakir telah tersedian di kawasan pantai sanggar. Untuk tempat parkir kendaraan roda empat di parkir di depan halaman rumah warga, sedangkan untuk yang kendaraan roda dua dapat mempunyai di parkir di sekitar kawasan pantai sanggar.

\section{3) Analisis}

Kawasan Pantai Sanggar sudah tersedian tempat parkir yang terdapat di permukiman dan pantai. Untuk tempat parkir yang berada dipantai bentuk bangunannya sudah sesuai dengan ketentuan yaitu tidak menebang/merusak pohon, pengerasan areal tidak mengganggu penyerapan air didalam tanah.

\section{E. Kantor pusat informasi dan pelayanan, pos keamanan}

1) Kebijakan/teori

Menurut Peraturan Direktur Jendral Perlindungan Hutan dan Konservasi alam tentang Pembangunan Sarana Pariwisata. Fasilitas pelayanan umum dan kantor seperti kantor pusat informasi dan pelayanan bahan bangunan untuk pembangunan sarana wisata alam dan fasilitas yang menunjang kepariwisataan diutamakan menggunakan bahan-bahan dari daerah setempat atau sekitar lokasi. Dalam hal bahan bangunan tidak terdapat didaerah setempat sebagaimana dimaksud dapat menggunakan bahan bangunan dari luar daerah setempat yang tidak merusak kelestarian lingkungan.

2) Kondisi eksisting

Belum tersedia tempat Kantor pusat informasi dan pelayanan, pos keamanan.

3) Analisis

Kawasan wisata Pantai Sanggar Desa Jengglungharjo belum memiliki Kantor pusat informasi dan pelayanan, pos keamanan. Sehingga jika dibangun kantor pusat informasi dan pelayanan diutamakan menggunakan bahan-bahan dari daerah setempat atau sekitar lokasi. Dalam hal bahan bangunan tidak terdapat didaerah setempat sebagaimana dimaksud dapat menggunakan bahan bangunan dari luar daerah setempat yang tidak merusak kelestarian lingkungan.

\section{F. Pusat oleh oleh}

\section{1) Kebijakan/teori}

Inskeep (1991) ada beberapa komponen wisata yang selalu ada dan merupakan komponen dasar dari wisata, salah satunya yaitu fasilitas dan pelayanan wisata. Fasilitas tersebut misalnya, restoran dan berbagai jenis tempat makan lainnya, toko-toko untuk menjual hasil kerajinan tangan, cinderamata.

2) Kondisi eksisisting

Belum tersedia pusat oleh-oleh di kawasan Pantai Sanggar

3) Analisis

Kawasan wisata Pantai Sanggar Desa Jengglungharjo belum memiliki pusat oleh oleh. Seharusnya dalam pengembangan infrastruktur pendukung wisata pantai pusat oleh oleh dibutuhkan guna mempromosikan oleh oleh khas kawasan Pantai Sanggar.

\section{G. Penyediaan air bersih}

1) Kebijkan/teori

Menurut Peraturan Direktur Jendral Perlindungan Hutan dan Konservasi alam tentang. Fasilitas untuk menunjang sarana kepariwisataan berupa penyediaan jaringan air bersih dibangun dengan kententuan diupayakan di bangun dalam tanah, dalam hal yang tidak dimungkinkan dibangun dalam tanah 
sebagaimana dimaksud, maka dapat dibangun diatas permukaan tanah dengan memperhatikan nilai estetika

2) Kondisi eksisiting

Kawasan ini sudah dilayani oleh jaringan air bersih yang berasal dari sumur bor

\section{3) Analisis}

Sudah tersedia penyediaan air bersih di kawasan Pantai Sanggar. sehingga perlu optimalisasi penyediaan air bersih yang ada dikawasan pantai sanggar.

\section{H. Jaringan listrik}

1) Kebijakan/teori:

Dalam pengembangan infrastruktur pendukung ekowisata yang seharusnya tidak menimbulkan kerusakan pada lingkungan seperti menggunakan sumberdaya hemat energy seperti energy tenaga surya [2]

2) Kondisi eksisting:

Kawasan pantai sanggar belum terlayani jaringan listrik sehingga sumber listrik berasal dari generator listrik (genset).

3) Analisis

Kawasan Pantai Sanggar di desa jengglungharjo belum menggunakan jaringan listrik yang hemat energy, yang seharusnya dikawasan pantai sanggar menggunkan sumberdaya hemat energi seperti energy tenaga surya.

\section{Tempat sampah}

1) Kebijakan/teori

Dalam pengembangan infrastrukur yang ramah lingkungan di terapkan system daur ulang untuk itu perlu dilakukan melalui sistem yang terintegrasi dan direncanakan secara matang agar tercipta proses pengolahan sampah yang aman dan efektif, sehingga wisata tidak membuang sampah ke laut dan ke pantai.

2) Kondisi eksisting

Kawasan Pantai Sanggar belum memiliki fasilitas tempat sampah.

3) Analisis

Belum tersedia fasilitas tempat sampah dikawasan Pantai Sanggar, sehingga perlu dibuat sistem daur ulang pengelolaan sampah.

\section{J. Kondisi jalan}

\section{1) Kebijakan/teori}

Dalam mengembangkan ekowisata yaitu dengan meningkatkan akses ke/dari dan antar daerah tujuan ekowisata tanpa merusak aset utama ekowisata dan optimalisasi jalur transportasi darat.

2) Kondisi ekisisting

Kondisi jalan menuju kawasan wisata Pantai Sanggar masih berupa tanah liat. Untuk menuju kawasan wisata ini harus menempuh jarak $\pm 2 \mathrm{~km}$ dari rumah warga yang ada di Desa Jengglungharjo. Dan badan jalan tidak terlalu lebar, hanya sekitar \pm 2 meter.

\section{3) Analisis}

Sudah terdapat akses menuju ke Pantai Sanggar, namun jalanya masih berupa tanah liat (macadam). Sehingga perlu optimalisasi jalur transportasi darat menuju kawasan Pantai Sanggar.

\section{K. Rambu petunjuk jalan dan arah}

1) Kebijkan/teori

Menurut Peraturan Direktur Jendral Perlindungan Hutan dan Konservasi alam tentang Pembangunan Sarana Pariwisata. Fasilitas penunjang sarana kepariwisataan berupa papan petunjuk dibuat untuk menyangkut keselamatan dan keamanan. yang mudah dilihat.

2) Kondisi eksisiting

Rambu - rambu petunjuk jalan dan arah untuk menuju kawasan pantai sanggar belum tersedia. Namun saat ini telah tersedia gapura sebagai tanda memasuki kawasan Pantai Sanggar.

3) Analisis

Belum terdapat rambu rambu petunjuk arah dan jalan dikawasan Pantai Sanggar. seharusnya rambu rambu petunjuk jalan dan arah di buat di kawasan Pantai Sanggar untuk menyangkut keselamatan dan keamanan.

\section{Moda transportasi}

1) Kebijakan/teori

Dalam pengembangan infrastruktur pendukung wisata mengutamakan moda transportasi yang dikelola oleh masyrakat kawasan wisata tersebut guna memberikan keuntungan langsung bagi masyarakat setempat. (from, 2004 dalam damanik 2006).

2) Kondisi eksisting

Untuk menuju kawasan Pantai Sanggar hanya dapar dilalaui oleh kendaraan roda 2, dan sudah terdapat jasa ojek menuju kawasan pantai.

3) Analisis

Sudah terdapat namun kendaraan roda 2. Seharusnya mengoptilmalkan moda transportasi yang sudah ada guna memberikan keuntungan langsung bagi masyarakat setempat.

\section{KESIMPULAN}

Berdasarkan hasil dari karekteristik infrastrukutr pendukung wisata pantai Sanggar untuk kedepannya perlu perbaikan infrastrukur seperti kondisi jalan yang masih berupa tanah liat, tempat parkir yang belum tertata dengan rapi, toilet yang kondisinya hanya bisa digunakan untuk buang air kecil saja, rambu rambu petunjuk jalan yang belum ada dan masih menggunakan gapura sebagai tanda, sedangkan yang terakhir yaitu sarana amenitas yang masih sangat sederhana berupa tempat duduk. Sedangkan untuk infrastrukur yang belum ada seperti perlu diadakan seperti pusat souvenir, kantor pusat dan pelayanan, pos keamanan pelu di bangun guna mendukung perkembangan wisata pantai Sanggar kedepannya. 


\section{DAFTAR PUSATAKA}

[1] K. A. Agustina, "Studi: Pengembangan Kawasan wisata Budaya kota Surabaya," Institut Teknologi Sepuluh Nopember, 2011.

[2] H. F. Damanik, Janianto,.dan Weber, Perencanaan Ekowisata: dari Teori ke Aplikasi. Yogyakarta: Andi, 2006.

[3] D. Evitasari, "Studi "Studi Pengembangan Atraksi dan Wisata dan Sarana Pendukung Kegiatan Objek Wisata Waduk Wonorejo Kabupaten Tuloungagung," ITN MALNG, 2005.

[4] E. Inskeep, "Tourism Planning: An Integrated and Sustainable Development Approach, Van Nostrand Reinhold," 1991.

[5] "Laporan Akhir RIPPDA Tulungagung," 2016.

[6] W. D. McIntosh, Tourism: Principles, Practices, Philosophies. New York: John Wiley \&amp; Sons, Inc, 995.

[7] Musanef, Manajemen Usaha Pariwisata di Indonesia. Jakarta: PT Toko Gunung Agung, 1995.

[8] A. Y. Oka, Pengantar Ilmu Pariwisata. Bandung: Angkasa, 1996. 